\title{
Pyrolysis and Oxidation of PAN in Dry Air. Thermoanalytical Methods
}

\author{
Anna BIEDUNKIEWICZ* , Pawel FIGIEL, Marta SABARA \\ Institute of Materials Science and Engineering, West Pomeranian University of Technology, Szczecin, Poland
}

Received 10 October 2010; accepted 10 February 2011

\begin{abstract}
The results of investigations on pyrolysis and oxidation of pure polyacrylonitrile (PAN) and its mixture with N,Ndimethylformamide (DMF) under non-isothermal conditions at linear change of samples temperature in time are presented. In each case process proceeded in different way. During pyrolysis of pure PAN the material containing mainly the product after PAN cyclization was obtained, while pyrolysis of PAN+DMF mixture gave the product after cyclization and stabilization. Under conditions of measurements, in both temperature ranges, series of gaseous products were formed.

For the PAN-DMF system measurements at different samples heating rates were performed. The obtained results were in accordance with the kinetics of heterogeneous processes theory. The process rates in stages increased along with the temperature increase, and TG, DTG and HF function curves were shifted into higher temperature range. This means that the process of pyrolysis and oxidation of PAN in dry air can be carried out in a controlled way.

Keywords: PAN, DMF, pyrolysis, oxidation, thermoanalysis.
\end{abstract}

\section{INTRODUCTION}

Polyacrylonitrile (PAN) is a widely used precursor for manufacturing carbon materials with very interesting mechanical, electrical and magnetic properties and high thermal and chemical resistance. These materials found application in aircraft and automotive industry, in electronics and as adsorbents and filters for water and gases treatment [1-28]. Nowadays PAN is also used as precursor during synthesis of transition metals and silicon carbides and nitrides. [2].

The age of carbon fibres derived from PAN started in year 1960, when A. Shindo, for the first time, subjected polyacrylonitrile to oxidation, before the pyrolysis process [13].

Products of PAN pyrolysis form thermally stable, organized molecular structures when they are processed by appropriate thermal treatment in low temperature called stabilization process. Stabilization is usually carried out in air. It prevents polymer from decomposition during carbonization in high temperature.

Properties of carbon material derived from PAN depend on conditions of pyrolysis, parameters of thermal treatment in high temperature and on the structure of applied polymer materials. Knowledge of characteristics of PAN thermal conversions proceeding in various systems is therefore crucial. Carbon forming from PAN is a composed process. In practice it is realized according to different procedures $[5,6,9,12,14,17,20,22,24,26]$. During stabilization series of reactions proceed. Their sequence was determined on the basis of many scientific works initiated in the last century $[12,14,16]$.

Reaction of cyclization was recognized as the most important process. This could be initiated in different ways, depending on type of atmosphere, presence of copolymers and other system components [8,20]. In reaction of cyclization generated by nitrile groups

\footnotetext{
*Corresponding author. Tel.: +48-91-4494071; fax.: +48-91-4494356. E-mail address: anna.biedunkiewicz@zut.edu.pl (A. Biedunkiewicz)
}

polymerization the material containing segments of short, ladder molecules connected by sequences of unchanged PAN polymer is formed (oligomerization). Nitrogen in the nitrile group forms the bound with the carbon of neighbouring nitrile group in the polymer chain and the six-element ring is formed.

The properties of carbon materials obtained in PAN pyrolysis and oxidation process depend on many factors. While manufacturing material according to the adopted procedure the course of PAN pyrolysis process has to be determined.

\section{EXPERIMENTAL DETAILS}

The investigations of pyrolysis and oxidation in dry air of solid PAN and PAN dissolved in DMF were carried out. PAN (purchased from Sigma-Aldrich) and DMF having a purity of $99.9 \%$ (Sigma-Aldrich) were used. Synthetic air; (Messer, Germany) containing $20.5 \%$ of oxygen and the rest of nitrogen was used. Impurities level was as follows: $\mathrm{H}_{2} \mathrm{O}<10 \mathrm{ppm}, \quad \mathrm{CO}_{2}<0.5 \mathrm{ppm}, \quad \mathrm{NO}_{\mathrm{x}}<0.1 \mathrm{ppm}$ and hydrocarbons $<0.1 \mathrm{ppm}$ by volume.

Thermogravimetric TG-DSC measurements were performed under non-isothermal conditions at linear change of sample temperature in time. SDT Q600 apparatus (TA Instruments) was used. Gaseous products were identified by mass spectrometry method using Thermostar GSD 301 (Pfeifer Vacuum) apparatus. Weighed amounts of the samples were in the range of $20 \mathrm{mg}$. The temperature was set between $25^{\circ} \mathrm{C}$ and $800^{\circ} \mathrm{C}$. During the measurements temperature, $\mathrm{TG}, \Delta \mathrm{TG}$ and $\mathrm{HF}$ functions in time as well as the mass spectra of main gaseous products were recorded.

\section{RESULTS AND DISCUSSION}

Investigations on pyrolysis and oxidation of PAN are usually carried out by TG-DSC method. Comparing the DTA and DSC curves presented in works [4, 8, 20, 22] one can notice that shape of the first exothermal peak, related to stabilization process proceeding with oxide participation, is fuzzy or consists of two very close peaks. Elonga- 
tion of heating time of PAN sample in air or increasing of upper temperature above $289^{\circ} \mathrm{C}$ favours super-adsorption of oxygen, increase of carbonyl $\mathrm{C}=\mathrm{O}$ groups number, structural defects and degradation of ladder structure of polymer $[8,9,12]$. Maximal degradation rate occurs at temperature of about $380^{\circ} \mathrm{C}$ [9]. According to the authors of work [9] the upper temperature of stabilization should not exceed $289^{\circ} \mathrm{C}$.

Reaction of cyclization starts at temperature of $180^{\circ} \mathrm{C}$ and proceeds slowly up to $220^{\circ} \mathrm{C}$, above which temperature it proceeds very rapidly up to the temperature of $289^{\circ} \mathrm{C}$ [8]. The selected temperature from the range of $180^{\circ} \mathrm{C}-289^{\circ} \mathrm{C}$ and time or rate of sample heating determined sufficiently stable structure of carbon material after carbonization.

During preparation of carbides precursors DMF is used as the solvent of PAN [2]. This is the most polar solvent among the group of polyacrylonitrile solvents. It strongly solvates cations and less anions. Between PAN and DMF the strong intermolecular interaction is found, what facilitates solubility of polymer in it. A complex between PAN and DMF can be formed what hinders total evaporation of DMF during the sample drying. The total removal of DMF is possible at higher temperature under conditions of PAN pyrolysis. In work [6] the courses of the pyrolysis process of solid PAN and PAN dissolved in DMF were compared. Pyrolysis was carried out at temperature of $700{ }^{\circ} \mathrm{C}$. The gaseous products were identified by chromatographic and mass spectroscopy method. In both cases similar gaseous products were obtained. It should be added that DMF also occurred in gaseous phase what indicates strong interaction between DMF and PAN molecules. Presence of DMF in PAN pyrolysis process reduces the thermal effect of cyclization process, causes increase of initial temperature of cyclization and the maximal reaction rate of the reaction is shifted into lower temperature range.

During the heat treatment of PAN-DMF mixture in argon two peaks occurred at DTG curve [28-30]. The first, endothermic peak referred to the conversion proceeding with mass loss and was connected with evaporation of DMF, and the second exothermal peak was connected with process of PAN cyclization.

According the state-of-art, in case of solid PAN at lower temperature cyclization and stabilization can take place. It is possible to obtain a mixtures of the products of these processes. Their identification is important for process synthesis of carbon fibres designing and also for synthesis carbides from precursor which contains PAN dissolved in DMF $[2,31]$. Identification of cyclization and stabilization products is possible in oxidation process in air at higher temperature using TG-DSC-MS method. Additionally, the comparison of course of pyrolysis process of pure PAN and mixtures of PAN and DMF in air is necessary.

In case of PAN-DMF system the samples were first heated at $110^{\circ} \mathrm{C}$ to strip the major part of mainly nonbonded DMF. Under measurement conditions evaporation of non-bonded rests of DMF, PAN cyclization and proceeding in parallel desorption of DMF with its decomposition, then stabilization of PAN and oxidation of conversions products can take place.
In Fig. 1 the charts of $\mathrm{TG}_{\mathrm{u}}$ and $\mathrm{HF}$ in time for both cases are presented. In case of pure PAN in HF curve the high exothermal peak occurs referring to cyclization. The process proceeded with mass loss.

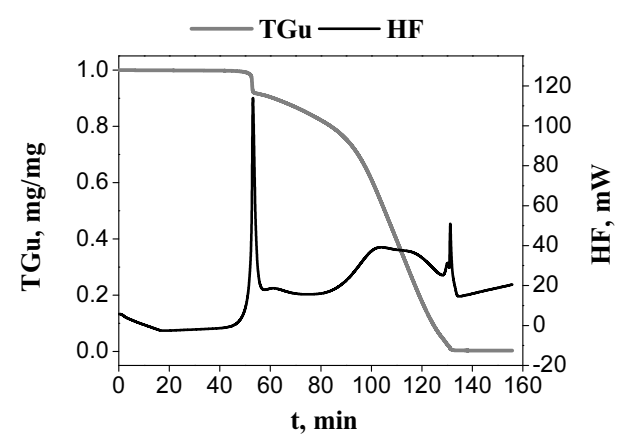

a

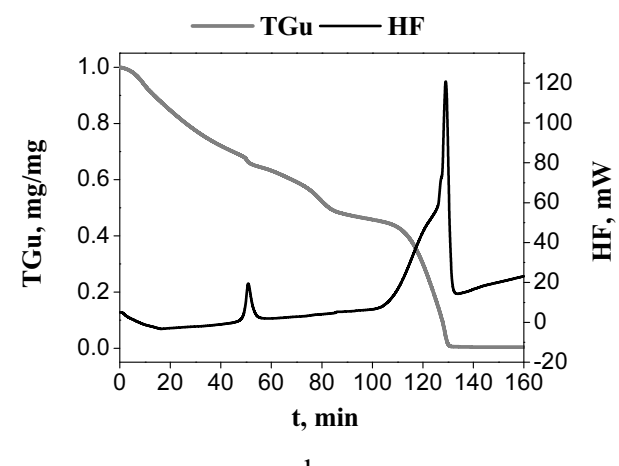

$\mathrm{b}$

Fig. 1. Normalized $\mathrm{TG}_{\mathrm{u}}$ and $\mathrm{HF}$ functions in time and in temperature. Sample heating rate: $5 \mathrm{~K} / \mathrm{min}, \mathrm{a}-\mathrm{PAN}$, $\mathrm{b}-\mathrm{PAN}+\mathrm{DMF}$

In case of PAN+DMF system the peak is low and shifted into the lower temperature range. The heat released during PAN cyclization was used during DMF desorption proceeding in parallel with cyclization.

The HF function curves in the range of reaction course of PAN conversion products oxidation are also different. In case of pure PAN first the wide peak referring to cyclization products combustion occurs and then a minor peak connected with combustion of cyclization products and PAN stabilization $[4,8,30]$. In case of PAN+DMF systems this relation is shifted in favour of second product. Performed measurements indicated also that under nonisothermal conditions process of polymer stabilisation did not proceed to completion.

In Fig. 2 TG and DTG functions in time are presented. In DTG curve concerning pure PAN two peaks occur. The first one refers to PAN cyclization and the second to oxidation of PAN conversion products at low temperature $[4,7,20]$. In case of PAN-DMF system in DTG curve four peaks are present. The first one concerns removal of free DMF rests, second one is connected with PAN cyclization process, the third one refers to desorption of DMF with its decomposition and the fourth one to oxidation of PAN conversion products formed at lower temperature.

An important complement of these measurements was identification of gaseous products. In both cases similar volatile products were evolved. In the range of lower temperature these were: $\mathrm{CO}_{2}, \mathrm{CH}_{3}, \mathrm{NO}, \mathrm{C}_{3} \mathrm{H}_{5}, \mathrm{C}_{3} \mathrm{H}_{6}$, $\mathrm{C}_{2} \mathrm{H}_{2} \mathrm{O}$. In case of $\mathrm{PAN}+\mathrm{DMF}$ system also DMF was 
registered. During oxidation of PAN conversion products the following compounds were formed: $\mathrm{CO}_{2}, \mathrm{NO}_{2}, \mathrm{C}_{3} \mathrm{H}_{5}$, $\mathrm{CH}_{3} \mathrm{CO}, \mathrm{C}_{2} \mathrm{H}_{5} \mathrm{O}, \mathrm{COOH}, \mathrm{C}_{2} \mathrm{H}_{7} \mathrm{~N}$. In both temperature ranges $\mathrm{HCN}$ and $\mathrm{NH}_{3}$ were not registered among evolved gases.

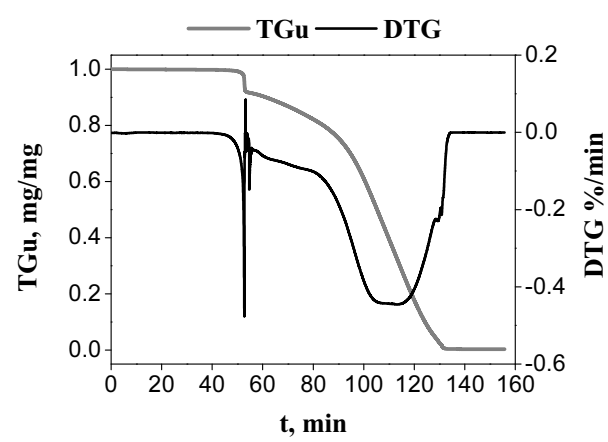

a

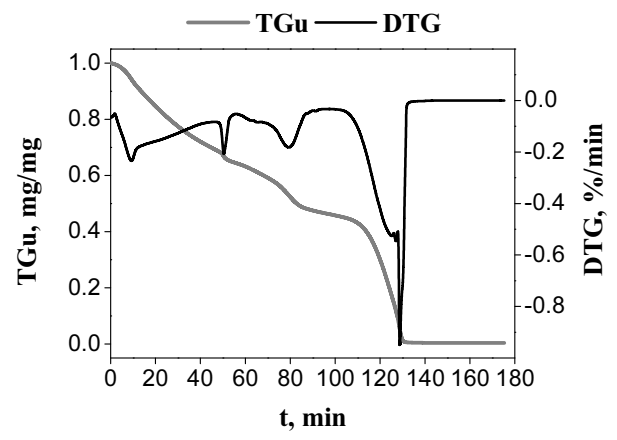

b

Fig. 2. Normalized $T_{\mathrm{u}}$ and $\mathrm{DTG}$ functions in time. Sample heating rate: $10 \mathrm{~K} / \mathrm{min}, \mathrm{a}-\mathrm{PAN}, \mathrm{b}-\mathrm{PAN}-\mathrm{DMF}$ system

In Fig. 3 mass spectra of the main gaseous components recorded during the proceeding of above mentioned processes is shown. The presented charts distinguish well both systems. It is evident that $\mathrm{CO}_{2}$ in case of pure PAN was educed during cyclization (first peak in the curve), during oxidation of PAN cyclization products (the first wide part of second peak) and during oxidation of the product after cyclization and stabilization (narrow part of second peak). Also other areas of the mass spectra curves are different.

In Fig. 4 mass spectra charts of products formed during the oxidation of PAN cyclization and stabilization products in dry air have been compared.

During combustion in both cases similar products were formed. It should be added that such products, except of $\mathrm{NO}_{2}$, were formed also during the PAN cyclization and DMF conversion. Course of PAN conversion depends also on sample heating rate. The influence of sample heating rate is shown at the example of PAN-DMF system.

The measurements were carried out at sample heating rate $2 \mathrm{~K} / \mathrm{min}$ (sample weight $19.59 \mathrm{mg}$ ), $5 \mathrm{~K} / \mathrm{min}$ (sample weight $19.58 \mathrm{mg}$ ) $10 \mathrm{~K} / \mathrm{min}$ (sample weight $20.45 \mathrm{mg}$ ). The second sample, after completion of the process, was heated for 3 hours under isothermal conditions.

The results of $\mathrm{TG}_{\mathrm{u}}$ and DTG function presented in Fig. 5 indicate, that registered variables are continuous functions of temperature and time. In Fig. 6 however DTG and HF function charts are shown.

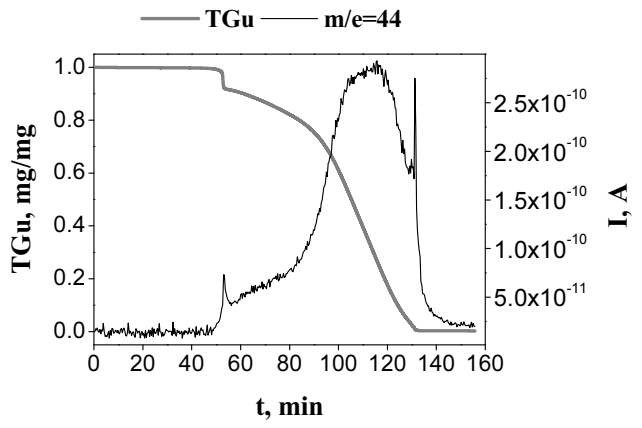

a

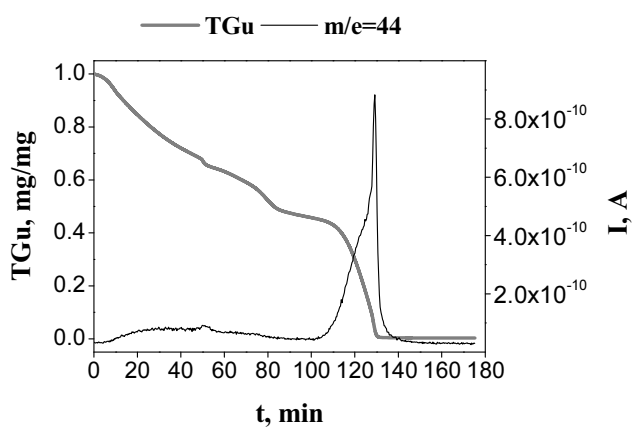

b

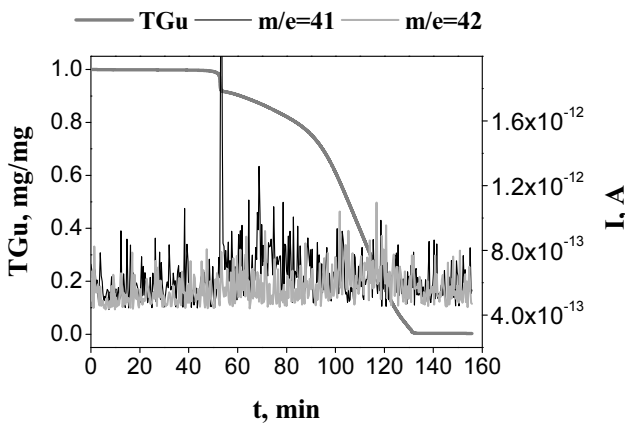

c

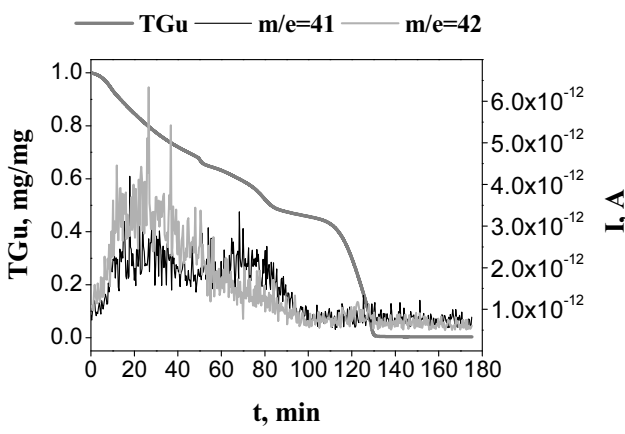

d

Fig. 3. Normalised $\mathrm{TG}_{\mathrm{u}}$ function and mass spectra: $\mathrm{a}-\mathrm{m} / \mathrm{e}=44$ $\left(\mathrm{CO}_{2}\right)$ concerns pure PAN system, $\mathrm{b}-\mathrm{m} / \mathrm{e}=44\left(\mathrm{CO}_{2}\right)$ concerns PAN -DMF system, c - m/e $=42 \quad\left(\mathrm{C}_{3} \mathrm{H}_{6}\right.$, $\left.\mathrm{C}_{2} \mathrm{H}_{2} \mathrm{O}\right)$ concerns pure PAN system, $\mathrm{d}-\mathrm{m} / \mathrm{e}=42\left(\mathrm{C}_{3} \mathrm{H}_{6}\right.$, $\mathrm{C}_{2} \mathrm{H}_{2} \mathrm{O}$ ) concerns PAN -DMF system. Sample heating rate: $5 \mathrm{~K} / \mathrm{min}$

At the used sample heating rates process stages were separated. In accordance with the theory of heterogeneous processes kinetics DTG and HF function curves were shifted into the higher temperature range while increasing 
sample heating rate. This means that the conversions can be conducted in a controllable way. It is evident that synthesizing precursors the samples can be heated up to the
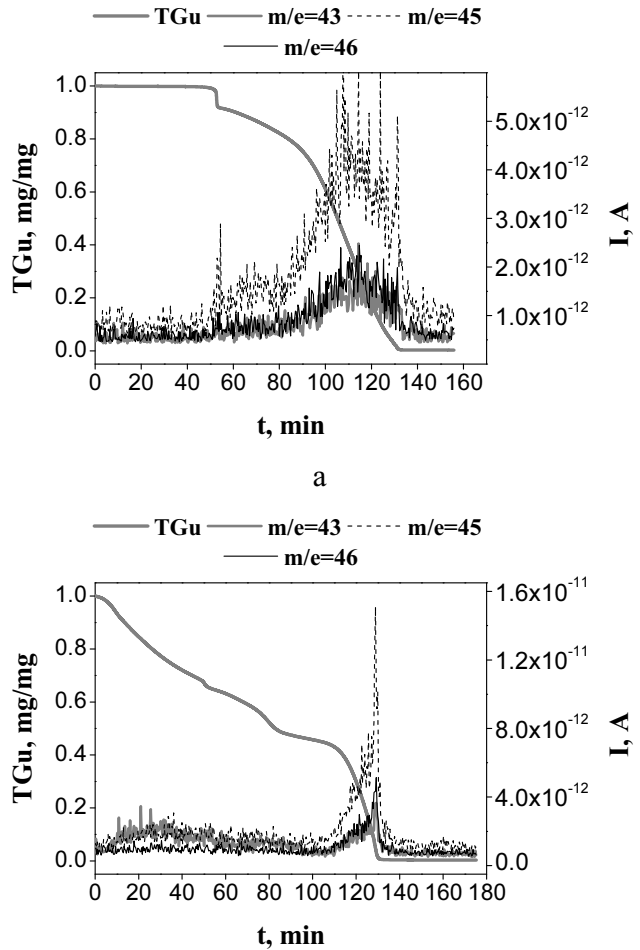

b

Fig. 4. Normalised $\mathrm{TG}_{\mathrm{u}}$ function and mass spectra: $\mathrm{m} / \mathrm{e}=43$ $\left(\mathrm{C}_{3} \mathrm{H}_{7}, \mathrm{CH}_{3} \mathrm{CO}\right), \mathrm{m} / \mathrm{e}=45\left(\mathrm{C}_{2} \mathrm{H}_{2} \mathrm{O}, \mathrm{COOH}, \mathrm{C}_{2} \mathrm{H}_{7} \mathrm{~N}\right)$ and $\mathrm{m} / \mathrm{e}=46\left(\mathrm{NO}_{2}\right) \cdot \mathrm{a}-\mathrm{PAN}, \mathrm{b}-\mathrm{PAN}-\mathrm{DMF}$. Sample heating rate: $5 \mathrm{~K} / \mathrm{min}$

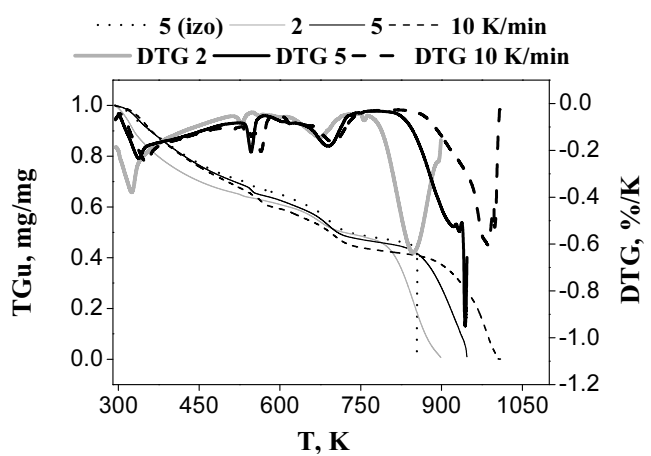

a

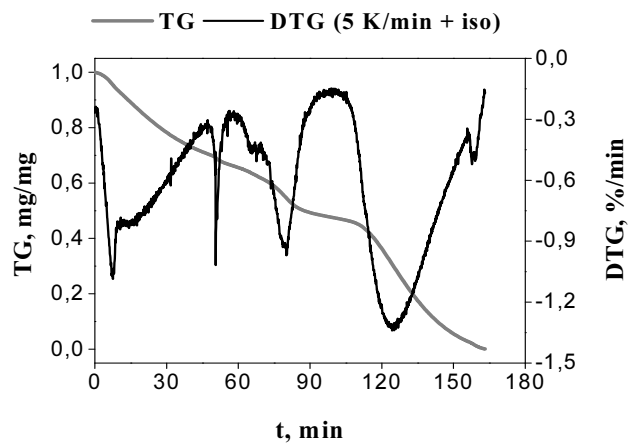

b

Fig. 5. $\mathrm{TG}_{\mathrm{u}}$ and DTG functions. Pyrolysis of PAN-DMF in dry air: $a$ - dependency on temperature, $b$ - dependency on time

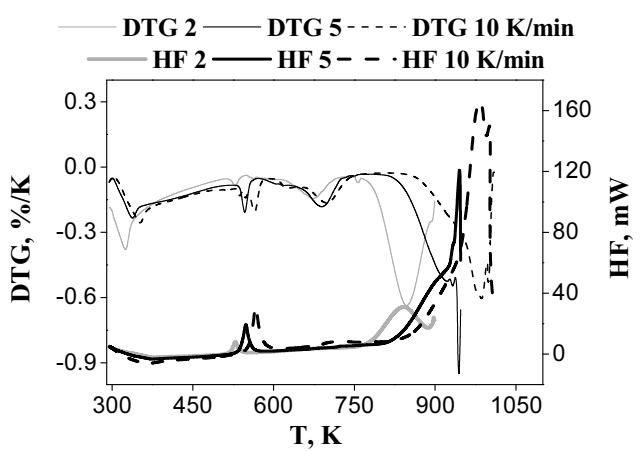

Fig. 6. DTG and HF functions chart. Oxidation of PAN-DMF in dry air

temperature range of $400{ }^{\circ} \mathrm{C}$ without generation of PAN cyclization and stabilization products conversion. This temperature was taken as suitable temperature for preparing precursors of carbides synthesis.

\section{CONCLUSIONS}

The results of investigations of pure PAN and PAN+DMF mixture pyrolysis and oxidation in dry air were presented. At the lower temperature range up to about $680 \mathrm{~K}$ cyclization and stabilization of PAN took place. At higher temperature oxidation of PAN conversion products formed at lower temperature proceeded. The course of processes was different. In case of pure PAN two stages, while in case of PAN+DMF system four stages were recorded.

In HF function curve obtained for pure PAN the high exothermal peak resulting from PAN cyclization occurred. Cyclization proceeded with the sample mass loss. During oxidation of PAN conversion products formed at lower temperature a double peak occurred in HF function curve. The first wide part referred to oxidation of cyclization products and the second narrow part of the peak concerned oxidation of PAN cyclization and stabilization products. In this case material containing mainly PAN cyclization product was obtained.

In case of PAN+DMF mixtures in HF function curve a peak connected with cyclization process occurred. The heat released during cyclization was used during desorption of DMF with its decomposition. In the range of oxidation course of PAN conversion products a narrow asymmetric peak was registered. In this case material after cyclization and stabilization was mainly obtained.

For PAN+DMF system measurements under nonisothermal conditions were performed at different sample heating rates in time. The obtained results are in accordance with theory of heterogeneous processes kinetics. Along with the increase of sample heating rate conversion rate in stages increased and the TG, DTG and HF function curves were shifted into higher temperature range. This means that pyrolysis and oxidation of PAN can be conducted in a controllable way.

\section{Acknowledgments}

Financial support of the work by the Ministry of Science and Higher Education within the project No. N N507 444334, 2008-2011, is gratefully acknowledged. 


\section{REFERENCES}

1. Wang, Yu, Santiago-Aviles, J. J., Furlan, R., Ramas, J. Pyrolisis Temperature and Tine Dependence of Electrical Conductivity for Electrostatically Generated Carbon Nanofibers IEEE Transaction on Nanotechnology 2 (1) 2003: pp. $39-43$.

2. Biedunkiewicz, A. Aspects of Manufacturing of Ceramic Nanomaterials of Type TiC/C, TiC, TiC-SiC-C and $\mathrm{Ti}(\mathrm{C}, \mathrm{N})-$ $\mathrm{Si}(\mathrm{C}, \mathrm{N})-\mathrm{Si}_{3} \mathrm{~N}_{4}$ by sol-gel method Ed. WPUT., Szczecin, 2009.

3. Beyler, C. L., Hirschler, M. M. Thermal Decomposition of Polymers (Charper 7). Overview and Backgroundt SFPE Handbook of Fire Protection Engineering. $3^{\text {rd }}$ ed, Editor-inchief: Philip J. Di Nenno, PE NFPA, Quincy MA, 2001: pp. $110-131$.

4. Sazanow, Yu. N., Nud'ga, L. A., Novoselova, A. V., Ugolkov, V. L., Fedorova, G. N., Kulikova, E. M., Gribanov, A. V. Carbonization of Polyacrylonitrile Composites with Nitrogen- containing Cellulose Derivatives Russian Journal of Applied Chemistry 77 (4) 2004: pp. 639-644.

5. Memetea, L. T., Billingham, N. C., Then, E. T. H. Hydroperoxides in Polyacrylonitrile and Their Role in Carbon- fibre Formation Polymer Degradation and Stability 47 1995: pp. 189-201.

6. Mittal, J., Konno, H., Inagaki, M., Bahl, O. P. Denitrogenation Behaviour and Tensile Strength Increase During Carbonization of Stabilized PAN Fibres Carbon 39 (9) 1998: pp. $1327-1330$.

7. Fitzer, E. PAN- Based Carbon Fibers - Present State and Trend of Technology from the Viewpoint of Possibilities and Limits to Influence and to Control the Fiber Properties by the Process Parameters Carbon 27 (50) 1989: pp. $621-645$.

8. Fitzer, E., Müller, D. J. The Influence of Oxygen on the Chemical Reactions During Stabilization of PAN as Carbon Fiber Precursor Carbon 13 1975: pp. 63-69.

9. Tse-Nao, K., Ching-Chyuan, Y., Wen-Tong, C. The Effect of Stabilization of PAN- Based Carbon Films Carbon 11 (4) 1993: pp. 583-590.

10. Morita, K.-T., Miyachi, H., Hiramatsu, T. Stabilization of Acrylic Fibers by Sulfur Atoms Mechanism of Stabilization Carbon 19 1981: pp. 11-18.

11. Deurebergue, A., Oberlin, A. TEM Study of Some Recent High Modulus PAN-Based Carbon Fibers Carbon 30 (7) 1992: pp. $981-987$.

12. Bahl, O. P., Manocha, L. M. Characterization of Oxidized PAN Fibers Carbon 12 1974: pp. 417-423.

13. Chang, P.-H., Labes, M. M. New Route of Graphite Flakes and Films: Pyrolisis of Aromatic and Heteroaromatic Compounds under Dehydrogenation Conditions Chemistry of Materials 1 1989: pp. 523-525.

14. Ko, T.-H., Day, T.-C., Perng, J.-A. The Characterization of PAN-Based Carbon Fibers Developed by Two-Stage Continuous Carbonization Carbon 31 (5) 1993: pp. 765-771.

15. Tsuchiya, Y., Sumi, L. Thermal Decomposition Products of Polyacrylonitrile Journal of Applied Polymer Science 21 1977: pp. $975-980$.

16. Bashir, Z. A Critical Review of the Stabilization of Polyacrylonitrile Carbon 29 (8) 1991: pp. 1081-1090.

17. Kowbel, W., Hippo, E., Muridie, N. Influence of Graphitization Environment of PAN Based Carbon Fibers on Microstructure Carbon 27 (2) 1989: pp. 219-226.
18. David, L. I., Ismail, A. F. Influence of the Thermostabilization Process and Soak Time During Pyrolysis Process on the Polyacrylonitrile Carbon Membranes for $\mathrm{O}_{2} / \mathrm{N}_{2}$ Separation Journal of Membrane Science 213 2003: pp. 285-291.

19. Surianarayanan, M., Panduranga, Rao, S., Vijayaraghavan, R., Raghvan, K. V. Thermal Behaviour of Acrylonitrile Polymerization and Polyacrylonitrile Decomposition Journal of Hazardous Materials 62 1998: pp. $187-197$.

20. Martin, S. C., Liggat, J. J., Snape, C. E. In Situ NMR Investigation into the Thermal Degradation and Stabilisation of PAN Polymer Degradation and Stability 74 2001: pp. $407-412$.

21. Nielsen, M., Jurasek, P., Hayashi, J., Furimsky, E. Formation of Toxic Gases During Pyrolysis of Polyacrylonitrile and Nylons Journal of Analytical and Applied Pyrolysis 35 1995: pp. 45-51.

22. Surianarayanan, M., Uchida, T., Wakakura, M. Evolved Gases by Simultaneous TG-MS Technique and Associated Thermal Hazard in Drying of Polyacrylonitrile Journal of loss Prevention in the Process Industries 11 1998: pp. $99-108$.

23. Setnescu, R., Jipa, S., $\quad$ Setnescu, T., $\quad$ Kappel, W., Kobayashi, S., Osawa, Z. IR and X-ray Characterization of Ferromagnetic Phase of Pyrolysed Polyacrylonitrile Carbon 37 1999: pp. 1-6.

24. Fitzer, E., Frons, W., Heine, M. Optimization of Stabilization and Carbonization Treatment of PAN Fibres and Structural Characterization of the Resulting Carbon Fibers Carbon 24 (4) 1986: pp. 387-395.

25. Paulauskas, F. L., Spruiell, J. E. Structure and Properties of Carbon Fibres Produced Using Microwave- Assisted Plasma Technology. Part 1 SAMPE Journal 40 (4) 2004: pp. $6-14$.

26. Chen, J., Harrison, I. R. Modyfication of Polyacrylonitrile (PAN) Carbon Fiber Precursor via Post-Spinning Plasticization and Stretching in Dimethyloformamide (DMF) Carbon 40 (1) 2002: pp. 25-45.

27. Laffont, L., Monthioux, M., Sern, V., Mathur, R. B., Guimon, C., Guimon, M. F. An EELS Study of the Structural and Chemical Transformation of PAN Polymer to Solid Carbon Carbon 42 (12-13) 2004: pp. 2485-2494.

28. Saufi, S. M., Ismail, A. F. Development and Characterization of Polyacrylonitrile (PAN) Based Carbon Hollow Fiber Membrane Songklanakarin Journal of Science and Technology 24 2002: pp. 843-854.

29. Aviles, M. A., Gines, J. M., del Rio, J. C., Pascual, J., Perez-Rodriguez, J. L., Sanchez-Soto, P. J. Thermal Analysis of Acrylonitrile Polymerization and Cyclization in Presence of N,N-dimethyloformamide Journal of Thermal Analysis and Calorimetry 67 2002: pp. 177-188.

30. Sanchez-Soto, P. J., Aviles, M. A., del Rio, J. C., Gines, J. M., Pascual, J., Perez-Rodriguez, J. L. Thermal Study of the Effect of Several Solvents on Polymerization of Acrylonitrile and Their Subsequent Pyrolysis Journal of Analytical and Applied Pyrolysis 58-59 2001: pp. $155-172$.

31. Biedunkiewicz, A., Gabriel, U., Figiel, P., Grzesiak, D. Application of Thermal Analysis in Nanotechnology. Carbonization and Purification of $\mathrm{nc}^{-\mathrm{TiC}_{\mathrm{x}}}$ in Argon Atmosphere Journal of Thermal Analysis and Calorimetry 101 (2) 2010: pp. 701-706.

Presented at the International Conference

"Baltic Polymer Symposium'2010"

(Palanga, Lithuania, September 8-11, 2010) 